JGG 2021;69:133-136

doi: 10.36150/2499-6564-N295

\title{
Physical activity programs in older persons with Alzheimer's disease: a need for dedicated trials
}

\author{
Tommaso Di Libero ${ }^{1}$, Elisa Langiano², Carlo Dimeo³ \\ Angela Marie Abbatecola ${ }^{4,5}$ \\ ${ }^{1}$ Alzheimer Disease Day Center, Casa della Salute Atina, Frosinone, Italy; ${ }^{2}$ Dipartimento di Scienze \\ Umane Sociali e della Salute, Università degli Studi di Cassino e del Lazio Meridionale, Italy; \\ ${ }^{3}$ Dipartimento di Geriatria, Ospedale Santa Scolastica, ASL Frosinone, Italy, ${ }^{4}$ Alzheimer Day Clinic, \\ Azienda Sanitaria Locale (ASL) di Frosinone, Italy; ${ }^{5}$ Società Italiana di Geriatria e Gerontologia \\ (SIGG), Biogerontology Section Coordinator, Florence, Italy
}

Received: October 13, 2020

Accepted: November 6, 2020

\section{Correspondence}

Tommaso Di Libero

Alzheimer Disease Day Center, Casa della Salute Atina, via Ponte Melfa 75, 03042 Atina (FR), Italy. E-mail:0032439@studentmail.unicas.it

\section{Conflict of interest}

The Authors declare no conflict of interest

How to cite this article: Di Libero $\mathrm{T}$, Langiano E, Dimeo C, et al. Physical activity programs in older persons with Alzheimer's disease: a need for dedicated trials. Journal of Gerontology and Geriatrics 2021;69:133-136. https://doi. org/10.36150/2499-6564-N295

C Copyright by Società Italiana di Gerontologia e Geriatria (SIGG)

\section{(c) (i) () $\odot$}

\section{OPEN ACCESS}

This is an open access article distributed in accordance with the CC-BY-NC-ND (Creative Commons Attribution-NonCommercial-NoDerivatives 4.0 International) license. The article can be used by giving appropriate credit and mentioning the license, but only for non-commercial purposes and only in the original version. For further information: https://creativecommons.org/licenses/by-nc-nd/4.0/deed.en
Recent works highlight the influence of different aspects of lifestyle on cognitive decline and the risk of dementia. Some data suggest that exercise could improve cognitive performance, especially executive functions and reduce the risk of cognitive decline and dementia in the elder. There is controversial data regarding the role of physical exercise on cognitive performance in older patients with dementia, which may be due to diverse study designs.

Innovative interventional trials need to adapt their aims toward physical and cognitive changes in patients suffering from Alzheimer's disease $(A D)$ in association with physical activity (PA). Future goals should include specific Adapted Physical Activity (APA) intervention programs on maintaining cognitive, emotional, and physical function in older persons with dementia at risk of rapid decline. In this commentary, we will provide novel insights on the use of potential physical activity programs in Alzheimer's Disease Day Centers.

Key words: Alzheimer's Disease, CDA, Day Center, physical activity, Ider people, exercise, lifestyle, dementia, cognitive decline, physical benefits, psychophysical benefits, AFA, inactivity, cognitive stimulation, prevention, physical exercise programs

\section{INTRODUCTION}

Dementia is a rapidly growing public health concern with currently approximately 50 million cases worldwide and nearly 10 million new cases every year. There is an estimated increase in dementia reaching 82 million in 2030 and 152 million in $2050^{1}$. This increase parallels a significant rise in healthcare costs for governments, communities, as well as families. In 2015, global social cost for treating dementia was approximately 818 billion US dollars, equivalent to $1.1 \%$ of global gross domestic product (GDP). Crucially, while advanced age is associated with a risk of cognitive decline, dementia is not a natural or inevitable consequence of ageing. Several recent studies have shown a relationship between the development of cognitive impairment and dementia with modifiable lifestyle factors, such as physical inactivity, tobacco use, unhealthy diets and alcohol abuse ${ }^{2}$. There are also specific disease states, including hypertension, diabetes, hypercholesterolemia, obesity and depression, well known risk factors significantly associated with 
an increased the risk of dementia. Other potentially risk factors include social isolation and cognitive inactivity ${ }^{3}$ only few European countries have so far recognized their pivotal role in care provision. The aim of this study is to provide additional evidence in this regard, based on the experience of Italian caregivers, analysed via a qualitative methodology, to take into account behaviours and perspectives of both spouses/partners and children/ children-in-law. Six semi-structured face-to-face indepth interviews were carried out. Five themes emerged: 1. Thus one may hypothesize that an improvement in modifiable risk factors also prevents the development of dementia or potentially halt the risk for cognitive decline in early stage diagnosis ${ }^{4}$.

\section{THE USE OF ADAPTED PHYSICAL ACTIVITY (APA) PROGRAMS}

Due to the limited efficacy of anti-dementia drug treatments, future research needs to aim at combining both psychosocial and physical activity according to available different environments. The increase in the aging population paralleled by a constantly growing rise in $A D$ cases and a progressive reduction in regular physical activity in older adults underlines the need to develop specific APA programs to improve/maintain functional and cognitive performance. Alzheimer's Disease (AD) Day Centers may represent an essential starting ground that includes social and health skills for specific individual needs with integrated, flexible and continuous care control that allows for dedicated APA program trials. It is widely known that AD centers assist patients with dementia, including those with behavioral disorders. Interventions tailored to caregivers may also hold role on reducing caregiver burden stress and the role of AD centers on reducing such stress should be further investigated ${ }^{5}$. The potential influence of interpersonal and environmental factors have shown to hold a potential impact on adherence to physical activity programs in older stroke patients ${ }^{6}$. In addition, a main goal of $A D$ day centers is to postpone institutionalization and limit improper hospitalizations, which in turn significantly reduces healthcare costs both directly and indirectly. ADA programs may improve functional skills to regain individual independency. The aim of combining ADA programs and cognitive stimulation in a randomized clinical trial, in particular, in AD Day Centers, may hold an important role on improving physical performance abilities, protecting against disability and potentially improving cognitive status. At the same time, ADA programs in AD Day centers may also provide an important goal toward educating patients on performing an active lifestyle, as well as improving psycho-physical well-being, avoiding the onset of musculoskeletal problems through the use of low mechanical impact and a progressive load increase, especially in strength training ${ }^{7}$. Considering the limited use of drug therapy in patients with moderate $A D$, there is an increasing interest in clinical trials testing the combination of drug treatments and ADA programs. Cognitive rehabilitation aims at achieving an optimal level of physical, psychological and social functions with a specific task. APA programs with 60-minute activity program in combination with motor reactivation (passive gymnastics with cognitive stimulation), manual-expressive occupational therapy, training for cognitive disorders (both on an individual as well as group interaction), sensor neural stimulation and music therapy merits investigation on protecting against cognitive decline in older adults with dementia. Other group activities, such as group psychotherapy, garden therapy and recreational activities may also improve personal emotional status ${ }^{8}$. Table I summarises some of the APA programs proposed in previous studies. Due to the fact that the literature regarding physical activity programs in older persons with dementia are not heterogeneous in terms of physical activity definitions, assessment periods, duration, and intensity, clinical outcomes from these trials do not provide clear indications ${ }^{9}$. Some studies have based their physical activity categorizations on available recommendations for health promotion, thus suggesting that such recommendations may also apply to AD prevention. However, from a practical perspective, it remains unclear which types or combination of leisure-time physical activities in which intensity, frequency, and duration are needed to reduce the risk or delay the onset of $A D$. The available literature mainly includes observational data and thus conclusions can only suggest potential roles. Up to now, a review conducted analyses regarding randomized controlled trials (RCTs) of physical activity on cognitive performance in older persons have reported overall beneficial effects on dementia incidence 9 . One of the main limitations of RCTs in older persons is their short duration period. However, the 24-month LIFE randomized clinical trial underlined that moderateintensity physical activity program reduced cognitive frailty compared with a health education program in sedentary older persons over a 24 month follow-up period ${ }^{10}$. A recent review testing the role of combined physical activity and exercise also implicated a potential role on improving cognitive performance ${ }^{11}$. Previous prevention trials with single-domain lifestyle interventions involving physical activity, diet, or management of vascular factors yielded disappointing or only modest results ${ }^{12}$. The focus of prevention trials has now shifted toward longer-term interventions (2-6 years) targeting simultaneously on multiple risk factors. Preventive 
Table I. Summary of APA programs presented in previous works.

\begin{tabular}{|c|c|c|c|c|}
\hline Time & Physical activity & Results & Potential benefits & Reference \\
\hline $\begin{array}{l}15 \text { minute } \\
\text { program } / 3 \text { times } \\
\text { a week }\end{array}$ & $\begin{array}{l}\text { Walking, hiking, bicycling, } \\
\text { aerobics or calisthenics, } \\
\text { swimming, water } \\
\text { aerobics, weight training } \\
\text { or stretching, or other } \\
\text { exercise. Subjects who } \\
\text { exercised at least } 3 \text { times } \\
\text { per week, above the lowest } \\
\text { quartile, were classified as } \\
\text { exercising regularly }\end{array}$ & $\begin{array}{c}\text { Regular exercise is } \\
\text { associated with a delay } \\
\text { in onset of dementia and } \\
A D \text {, further supporting its } \\
\text { value for older persons }\end{array}$ & $\begin{array}{l}\text { Provides evidence on } \\
\text { maintaining good quality of life, } \\
\text { health and physical function } \\
\text { Reduces falls in older persons } \\
\text { especially in those with } \\
\text { comorbidities }\end{array}$ & $\begin{array}{l}(4,16) \text { Seattle, Washington. } \\
\text { Participants: } 1740 \text { persons } \\
\text { older than age } 65 \text { years without } \\
\text { cognitive impairment who scored } \\
\text { above the } 25 \text { th percentile on } \\
\text { the Cognitive Ability Screening } \\
\text { Instrument (CASI) }\end{array}$ \\
\hline $\begin{array}{l}\text { 60-minute } \\
\text { program/3-4 } \\
\text { times a week }\end{array}$ & $\begin{array}{l}\text { The intervention involves } \\
\text { activities including walking, } \\
\text { ankle weights, balance } \\
\text { exercises and stretching }\end{array}$ & $\begin{array}{c}\text { Provides relevant } \\
\text { findings on a broad range } \\
\text { including health, frailty, } \\
\text { behavioral outcomes, } \\
\text { biomarkers, and imaging }\end{array}$ & $\begin{array}{l}\text { Passive gymnastics with } \\
\text { cognitive stimulation, manual- } \\
\text { expressive occupational } \\
\text { therapy, training for cognitive } \\
\text { disorders, sensor neural } \\
\text { stimulation and music therapy } \\
\text { merits further investigation on } \\
\text { protecting against cognitive } \\
\text { decline in older adults with } \\
\text { dementia }\end{array}$ & $(6,7)$ \\
\hline $\begin{array}{l}150 \text { minute } \\
\text { program/3 times } \\
\text { a week }\end{array}$ & $\begin{array}{c}\text { Aerobics, strength and } \\
\text { balance exercises. Tai chi, } \\
\text { pilates, dance Cognitive } \\
\text { training }\end{array}$ & $\begin{array}{c}\text { Persons achieving } \\
\text { recommended levels } \\
\text { of PA reported fewer } \\
\text { unhealthy days compared } \\
\text { with inactive and } \\
\text { insufficiently active } \\
\text { persons. Physical training } \\
\text { improved cognitive } \\
\text { performance and was } \\
\text { associated with increased } \\
\text { hippocampal volumes }\end{array}$ & $\begin{array}{l}\text { Exercise training in older } \\
\text { patients is associated with } \\
\text { reduced cardiovascular } \\
\text { mortality. Exercise may also be } \\
\text { beneficial on executive function. } \\
\text { Balance training should also be } \\
\text { recommended to reduce falls }\end{array}$ & $\left({ }^{14,15,17,18}\right)$ \\
\hline $\begin{array}{l}150 \text { minute } \\
\text { programweek } \\
\text { over } 24 \text { months }\end{array}$ & $\begin{array}{l}\text { Walking, in addition to } \\
\text { strength, flexibility, and } \\
\text { balance training }\end{array}$ & $\begin{array}{c}\text { Moderate physical activity } \\
\text { intensity program reduced } \\
\text { the severity of cognitive } \\
\text { frailty among sedentary } \\
\text { older persons over } 24 \\
\text { months }\end{array}$ & $\begin{array}{l}\text { A long term structured, } \\
\text { moderate-intensity physical } \\
\text { activity program holds an } \\
\text { important basis for reducing } \\
\text { cognitive frailty compared to } \\
\text { health education programs in } \\
\text { sedentary older persons }\end{array}$ & $\left({ }^{10,13}\right)$ \\
\hline
\end{tabular}

multi-domain lifestyle interventions, including physical activity, cognitive training and correct dieting showed to protect that multi-domain interventions were associated with improved as well as maintained cognitive performance in older persons without dementia ${ }^{13}$.

\section{PHYSICAL EXERCISE PROGRAMS}

Prospective studies indicate that physical inactivity is one of the most common preventable risk factors for developing $A D$ and that higher physical activity levels are associated with a reduced risk of development of disease ${ }^{14}$. Physical exercise protects against the degeneration of cognitive performance in dementia. Evidence from both animal and human studies supports the role of physical exercise in modifying metabolic, structural, and functional dimensions of the brain and preserving cognitive performance in older adults ${ }^{15}$. Physical exercise interventions and regular physical exercise programs have shown to improve neuroprotective mechanisms and exercise programs that are structured, individualized, high intensity, longer duration, and multicomponent may hold a more definitive goal for preserving cognitive performance in older adults ${ }^{15}$. Moreover, cognitive disorders along with behavioural disturbances may also benefit from both APA and physical exercise programs. 


\section{CONCLUSIONS}

$A D$ represents the most common form of dementia with a progressive neurodegenerative impairment that causes losses in cognitive performance, especially short-term memory loss, heavy social burden as well as an increased risk for morbidity and mortality. Physical activity, exercise programs and cognitive training have all shown in a separate manner to influence both functional and cognitive performance. Therefore, specifically designed multi-domain strategies including physical activity, physical exercise and cognitive stimulation may hold a beneficial role on protecting against cognitive decline in older persons with mild or moderate AD. Indeed, there is an important need to formulate dedicated clinical trials and $A D$ day centers offer a distinct environment for such trials that should hold clear intervention criteria, large samples, and long-term follow-up on investigating such parameters in older AD patients.

\section{References}

1 Adelina C. The costs of dementia: advocacy, media and stigma. Alzheimer's Dis Int World Alzheimer Rep 2019;2019:100-1.

2 Dua T, Seeher KM, Sivananthan S, et al. World Health Organization'S Global Action Plan on the Public Health Response To Dementia 2017-2025. Alzheimer's Dement 2017;13:P1450-1. https://doi.org/10.1016/j. jalz.2017.07.758

3 Papa R, Lamura G. The caregivers' iceberg: qualitative narratives of Italian caregivers' roles and challenges. Journal of Gerontology and Geriatrics 2019;67:156-67.

4 Hussenoeder FS, Riedel-Heller SG. Primary prevention of dementia: from modifiable risk factors to a public brain health agenda? Soc Psychiatry Psychiatr Epidemiol 2018;0:0. https://doi.org/10.1007/s00127-018-1598-7

5 Beinart N, Weinman J, Wade D, et al. Caregiver burden and psychoeducational interventions in Alzheimer's Disease: a review. Dement Geriatr Cogn Dis Extra 2012;2:638-48. https://doi.org/10.1159/000345777

6 Dahlan Tabah FT, Sham F, Zakaria FN, et al. Factors influencing stroke patient adherence to physical activity: a systematic review. Journal of Gerontology and Geriatrics 2020;1-6. https://doi.org/10.36150/2499-6564-389

7 Pahor M, Guralnik JM, Anton SD, et al. Impact and lessons from the Lifestyle Interventions and Independence for
Elders (LIFE) clinical trials of physical activity to prevent mobility disability. J Am Geriatr Soc 2020;68:872-81. https:// doi.org/10.1111/jgs.16365

8 Woods B, Aguirre E, Ae S, et al. Strange but true: earth is not round. Scientific Am 2012;2. https://doi. org/10.1002/14651858.CD005562.

9 Du Z, Li Y, Li J, et al. Physical activity can improve cognition in patients with alzheimer's disease: a systematic review and meta-analysis of randomized controlled trials. Clin Interv Aging 2018;13:1593-603. https://doi.org/10.2147/ CIA.S169565

10 Liu Z, Hsu FC, Trombetti A, et al. Effect of 24-month physical activity on cognitive frailty and the role of inflammation: the LIFE randomized clinical trial. BMC Med 2018;16:1-10. https://doi.org/10.1186/s12916-018-1174-8

11 Jia RX, Liang JH, Xu Y, et al. Effects of physical activity and exercise on the cognitive function of patients with Alzheimer disease: a meta-analysis. BMC Geriatr 2019;19:181. https://doi.org/10.1186/s12877-019-1175-2

12 Bahar-Fuchs A, Clare L, Woods B. Cognitive training and cognitive rehabilitation for mild to moderate Alzheimer's disease and vascular dementia. Cochrane Database Syst Rev 2013;2013. https://doi.org/10.1002/14651858. CD003260

13 Ngandu T, Lehtisalo J, Solomon A, et al. A 2 year multidomain intervention of diet, exercise, cognitive training, and vascular risk monitoring versus control to prevent cognitive decline in at-risk elderly people (FINGER): a randomised controlled trial. Lancet 2015;385:2255-63. https://doi. org/10.1016/S0140-6736(15)60461-5

14 Cass SP. Alzheimer's disease and exercise: a literature review. Curr Sports Med Rep 2017;16:19-22. https://doi. org/10.1249/JSR.0000000000000332

15 Kirk-Sanchez NJ, McGough EL. Physical exercise and cognitive performance in the elderly: current perspectives. Clin Interv Aging 2013;9:51-62. https://doi.org/10.2147/ CIA.S39506

16 Larson EB, Wang L, Bowen JD, et al. Exercise is associated with reduced risk for incident dementia among persons 65 years of age and older. Ann Intern Med 2006;144:73-81. https://doi.org/10.7326/0003-4819-144-2-20060117000004

17 Langhammer B, Bergland A, Rydwik E. The importance of physical activity exercise among older people. Biomed Res Int2018;2018:3-6. https://doi.org/10.1155/2018/7856823

18 Kramer AF, Erickson Kl, Colcombe SJ. Exercise, cognition, and the aging brain. J Appl Physiol 2006;101:1237-42. https://doi.org/10.1152/japplphysiol.00500.2006 